\title{
OPTIMALISASI SISTEM PENYIMPANAN REKAM MEDIS DI PUSKESMAS PADANG
} PASIR TAHUN 2019

\section{OPTIMIZATION OF MEDICAL RECORDS STORAGE SYSTEM IN PADANG PASIR COMMUNITY HEALTH CENTER 2019}

\author{
Dewi Oktavia*
}

Ilmu Rekam Medis, Apikes Iris

email: dewioktavia_ph@yahoo.com

\begin{abstract}
ABSTRAK
Semua fasilitas pelayanan kesehatan wajib menyelenggarakan rekam medis, termasuk puskesmas. Dengan pelayanan rekam medis yang berkualitas pasien akan merasa puas, khususnya karena pasien dilayani dengan cepat, tepat dan aman oleh pihak puskesmas. Permasalahan yang sering ditemui pada bagian penyimpanan rekam medis adalah terjadinya misfile maupun duplikasi nomor rekam medis. Akibatnya, berkas rekam medis pasien lama sulit ditemukan sehingga proses pencarian berkas rekam medis pasien di rak penyimpanan membutuhkan waktu yang cukup lama. Tujuan pelaksanaan Pengabdian Kepada Masyarakat (PKM) agar sistem penyimpanan rekam medis menjadi optimal dalam rangka peningkatan kualitas pelayanan rekam medis pasien rawat jalan di Puskesmas Padang Pasir. Metode yang digunakan berupa sosialisasi tentang optimalisasi sistem penyimpanan rekam medis di Puskesmas Padang Pasir. Sebelum sosialisasi, dilakukan pre-test dan setelah sosialisasi dilakukan kegiatan post-test dengan tujuan mengetahui tingkat pemahaman mitra tentang materi sosialisasi. PKM ini dilakukan pada tanggal 9 bulan Agustus 2019 di Puskesmas Padang Pasir. Peserta dari kegiatan PKM ini adalah semua petugas rekam medis di Puskesmas Padang Pasir sebanyak 6 (enam) orang. Hasil dari kegiatan PKM ini adalah adanya peningkatan pengetahuan mitra tentang penyimpanan rekam medis dari nilai rata-rata 45 menjadi 85 point.
\end{abstract}

Kata Kunci : Kualitas, Pengabdian, Penyimpanan, Puskesmas, Rekam Medis

\section{ABSTRACT}

All health service facilities are required to hold medical records, including public health centers. With a quality medical record service, patients will feel satisfied, especially because patients are served quickly, precisely and safely by the community health centers. The problem that is often encountered in the medical records storage is the occurrence of misfiling and duplication of medical record numbers. As a result, old patient medical record files are difficult to find, so the process of searching a patient's medical record file on a storage rack takes quite a long time. The purpose of the implementation of Community Service (PKM) so that the medical record storage system becomes optimal to improve the quality of outpatient medical record services at the Padang Pasir Health Center. The method used in the form of socialization about optimizing the medical record storage system at the Padang Pasir Health Center. Before the socialization, a pre-test was carried out and after the socialization, a post-test was carried out to know the level of understanding of partners about the material of the socialization. This PKM was held on August 9 , 2019, at the Padang Pasir Communuty Health Center. The participants of this PKM activity are all 6 medical records officers at the Padang Pasir Health Center. The result of this PKM activity was an increase in partner knowledge about medical record storage from an average value of 45 to 85 points.

Keywords: Quality, Service, Storage, Community Health Centers, Medical Records

\section{PENDAHULUAN}

Puskesmas adalah fasilitas pelayanan

kesehatan yang menyelenggarakan kesehatan masyarakat dan upaya kesehatan perseorangan tingkat pertama, dengan lebih upaya mengutamakan upaya promotif dan preventif 
untuk mencapai derajat kesehatan masyarakat yang setinggi-tingginya di wilayah kerjanya [1].

Puskesmas menjadi rujukan pertama pelayanan kesehatan bagi masyarakat, sehingga harus dapat menjaga kepercayaan masyarakat. Pelayanan puskesmas yang berkualitas akan timbul kepercayan kepada masyarakat yang mengakibatkan pasien datang kembali, baik untuk berobat maupun hanya berkonsultasi tentang perkembangan kesehatannya secara loyal. Dengan demikian, tujuan puskesmas membangun masyarakat yang sehat, khususnya melalui program-program promotif dan rehabilitatif akan tercapai.

Semua fasilitas pelayanan kesehatan wajib menyelenggarakan rekam medis, termasuk puskesmas. Dengan pelayanan rekam medis yang berkualitas pasien akan merasa puas, khususnya karena pasien dilayani dengan cepat, tepat dan aman oleh pihak puskesmas. Ketersediaan berkas secara cepat dan tepat pada saat dibutuhkan akan sangat membantu mutu pelayanan kesehatan yang diberikan kepada pasien. Jika sistem penyimpanan berkas rekam medis yang dipakai kurang baik, akan timbul masalah-masalah yang dapat mengganggu ketersediaan berkas rekam medis.

Berdasarkan Peraturan Menteri Aparatur Negara (Permenpan) tentang Perekam Medis tahun 2013 dijelaskan bahwa kebutuhan tenaga rekam medis di Puskesmas itu adalah lima orang terampil dan dua orang ahli di bidang rekam medis [2]. Namun di Puskesmas Padang Pasir hanya terdapat satu orang ahli tenaga rekam medis yang berlatar belakang rekam medis.
Puskesmas Padang Pasir melayani 10 kelurahan dan saat ini memiliki sebanyak tiga orang dokter umum dan lima orang dokter gigi. Puskesmas Padang Pasir tidak hanya melayani pasien rawat jalan namun juga melayani pasien rawat inap. Jumlah kunjungan pasien rawat jalan di Puskesmas Padang Pasir mengalami peningkatan yaitu 82.720 orang pada tahun 2016 meningkat menjadi 102.583 orang pada tahun 2017 [3]. Meningkatnya jumlah kunjungan pasien pada Puskesmas Padang Pasir maka diharapkan juga adanya peningkatan pelayanan kesehatan di Puskesmas terutama pelayanan di bagian rekam medis karena pelayanan rekam medis merupakan pelayanan pertama yang diterima oleh pasien.

Permasalahan yang sering ditemui pada bagian penyimpanan rekam medis adalah terjadinya misfile maupun duplikasi nomor rekam medis [4]. Akibatnya, berkas rekam medis pasien lama sulit ditemukan sehingga proses pencarian berkas rekam medis pasien di rak penyimpanan membutuhkan waktu yang cukup lama. Menurut Budi (2011), beberapa fasilitas di ruang penyimpanan berkas rekam medis diantaranya ada (a) ruang dengan suhu ideal untuk penyimpanan berkas dan keamanan dari serangan fisik lainnya; (b) alat penyimpanan berkas rekam medis, bisa menggunakan roll $o$ pack, rak terbuka, dan filing cabinet; (c) tracer yang digunakan sebagai pengganti berkas rekam medis di rak filing yang dapat digunakan untuk menelusur keberadaan rekam medis [5].

Oleh karena itu, berdasarkan permasalahan yang telah dipaparkan tersebut, penulis tertarik 
untuk melakukan pengabdian masyarakat yang berhubungan dengan optimalisasi sistem penyimpanan rekam medis dalam rangka peningkatan kualitas pelayanan rekam medis pasien rawat jalan di Puskesmas Padang Pasir tahun 2019. Adapun tujuan khusus dari pengabdian kepada masyarakat ini adalah untuk meningkatkan pengetahuan petugas rekam medis di Puskesmas Padang Pasir khususnya sistem penyimpanan rekam medis yang optimal sehingga peningkatan kualitas pelayanan rekam medis pasien rawat jalan di Puskesmas Padang Pasir dapat tercapai.

\section{METODE PELAKSANAAN KEGIATAN}

Kegiatan pengabdian kepada masyarakat ini dimulai dengan melakukan survey awal ke Puskesmas Padang Pasir. Selanjutnya, ditetapkan topik yang perlu dilakukan untuk pengabdian kepada masyarakat ini yaitu permasalahan pada sistem penyimpanan rekam medis. Target sosialisasi adalah semua petugas di Puskesmas Padang Pasir Padang.

Pada tahapan pelaksanaan pengabdian, metode yang digunakan berupa sosialisasi tentang optimalisasi sistem penyimpanan rekam medis. Kegiatan dilanjutkan dengan diskusi dan tanya jawab terkait tentang sistem penyimpanan. Sebelum sosialisasi, petugas rekam medis diberikan pre-tes tentang sistem penyimpanan rekam medis. Setelah sosialisasi dilaksanakan, dilakukan lagi kegiatan post-test. Hal ini bertujuan untuk mengevaluasi tingkat pemahaman SDM terhadap materi yang telah disampaikan sebelum dan setelah dilakukannya kegiatan pelatihan. Dari data tersebut akan diketahui apakah kegiatan sosialisasi berjalan efektif dan mengenai sasaran.

Pelaksanaan kegiatan terdiri dari beberapa tahap:

1. Memberikan soal pre-test sebelum dilakukannya sosialisasi tentang teori penyimpanan rekam medis.

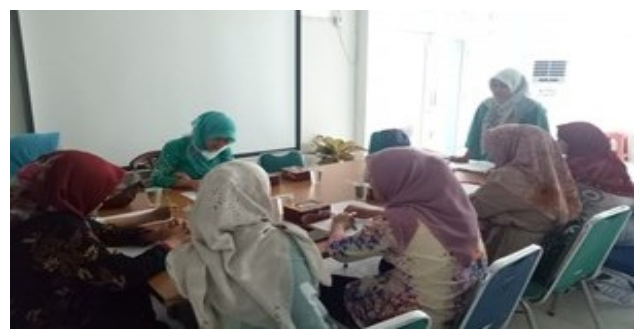

Gambar 1. Memberikan soal pre-test tentang penyimpanan rekam medis ke petugas rekam medis

2. Pelaksanaan sosialisasi, dengan materi kegiatan tentang sistem penyimpanan rekam medis yang optimal dalam rangka untuk meningkatkan mutu/kualitas pelayanan rekam medis pasien rawat jalan di Puskesmas Padang Pasir.

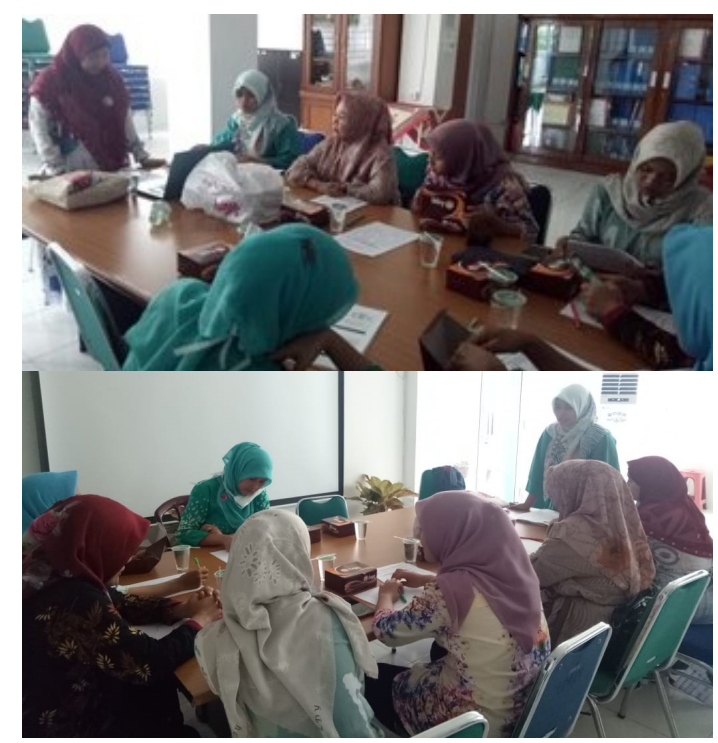

Gambar 2. Penyampaian materi tentang penyimpanan rekam medis

3. Memberikan soal post-test dari soal yang sama dengan soal pre-test untuk mengukur kemampuan pemahaman mitra. 


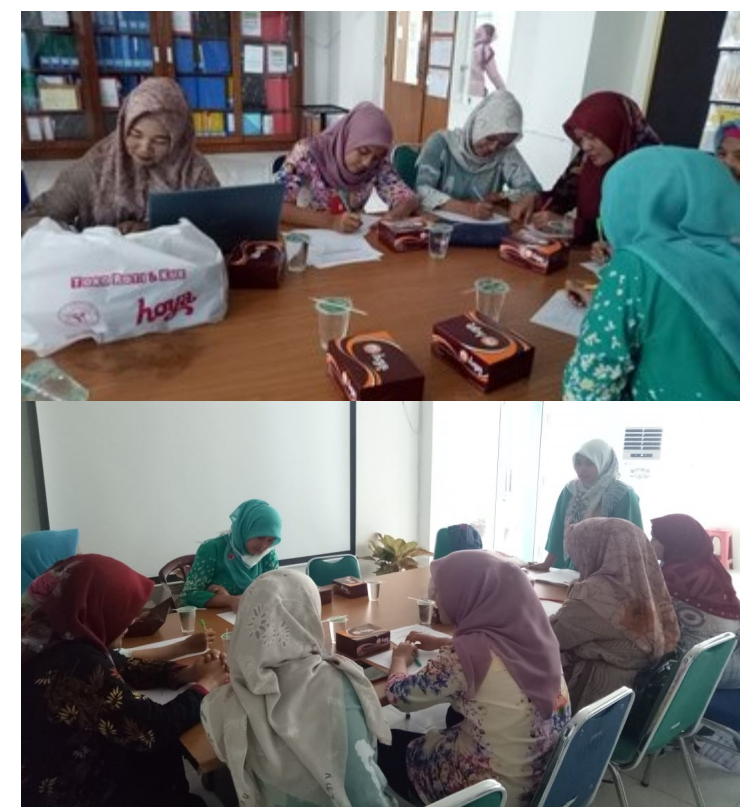

Gambar 3. Memberikan soal post-test yang sama dengan soal pre-test sebelumnya

Metode pelaksanaan pengabdian kepada masyarakat dilakukan dengan cara memberikan materi dan dipresentasikan serta didiskusikan dengan staf yang hadir dalam Pengabdian tersebut dengan beberapa tahap:

1. Pemaparan materi tentang sistem penyimpanan rekam medis yang dilakukan dengan cara memberikan informasi kepada pemberi pelayanan kesehatan khususnya bagian Rekam Medis pada kegiatan Pengabdian kepada masyarakat di Puskesmas Padang Pasir.

2. Tanya jawab dan diskusi

Pada tahapan ini diberi kesempatan kepada petugas rekam medis untuk bertanya tentang permasalahan yang terjadi di bagian penyimpanan rekam medis. Dari permasalahan tersebut diberikan solusi yang tepat dalam menghadapi permasalahan yang sering terjadi di bagian penyimpanan rekam medis Puskesmas Padang Pasir. Semua peserta diharapkan untuk ikut berpartisipasi dalam pelaksanaan tanya jawab ini.

3. Monitoring dan Evaluasi

Kegiatan selanjutnya adalah pelaksanaan post-test kepada petugas rekam medis untuk mengukur tingkat pengetahuan dan pemahaman petugas rekam medis setelah dilaksanakannya kegiatan sosialisasi sistem penyimpanan rekam medis yang baik ini.

\section{HASIL DAN PEMBAHASAN}

Pelaksanaan kegiatan sosialisasi ini dilakukan pada hari Jum'at tanggal 9 Agustus 2019 pukul 11.00 WIB di Puskesmas Padang Pasir. Kegiatan dimulai dari pembukaan oleh moderator. Moderator memperkenalkan diri dan menyampaikan tujuan dari kegiatan, lalu mendistribusikan soal pre-test. Setelah itu, moderator memberikan kesempatan waktu kepada pemateri untuk memaparkan tentang sosialisasi optimalisasi sistem penyimpanan rekam medis.

\section{Peserta dan lokasi}

Peserta yang hadir adalah semua petugas rekam medis sebanyak 6 (enam) orang. Lokasi kegiatan ini bertempat di ruangan aula Puskesmas Padang Pasir.

2. Proses

Secara keseluruhan kegiatan berjalan lancar, semua peserta yang hadir mengikuti kegiatan dari awal hingga akhir. Sebelum diberikan materi, kegiatan ini dimulai dari pemberian soal pre-test tentang penyimpanan rekam medis. Setelah pemberian materi, peserta diminta untuk menjawab soal post-test. Peserta yang hadir ikut berperan aktif saat sesi tanya jawab. 


\section{Output}

Adanya peningkatan pengetahuan petugas rekam medis setelah dilakukannya kegiatan sosialisasi. Hal ini bisa dilihat dari peningkatan kemampuan petugas rekam medis dalam menjawab soal post-test. Hasil nilai rata-rata pre-test diperoleh sebesar 45 point, meningkat menjadi 85 point setelah dilaksanakannya post-test. Hasil ini dapat dilihat pada tabel 1 di bawah ini:

Tabel 1. Nilai pre-test dan post-test

\begin{tabular}{|c|c|c|}
\hline \multirow{2}{*}{ Peserta } & \multicolumn{2}{|c|}{ Nilai } \\
\cline { 2 - 3 } & Pre-test & Post-test \\
\hline 1 & 34 & 84 \\
\hline 2 & 40 & 82 \\
\hline 3 & 42 & 85 \\
\hline 4 & 44 & 84 \\
\hline 5 & 42 & 82 \\
\hline 6 & 66 & 95 \\
\hline Jumlah & 268 & 512 \\
\hline Rata-Rata & 45 & 85 \\
\hline
\end{tabular}

\section{Outcome}

Dengan sosialisasi ini diharapkan sistem penyimpanan rekam medis di Puskesmas Padang Pasir lebih optimal agar dapat meningkatkan kualitas pelayanan rekam medis pasien yang mana pelayanan rekam medis pasien rawat jalan bisa mencapai standar pelayanan minimal rekam medis yakni maksimal 10 menit.

\section{Kendala}

a. Latar belakang pendidikan petugas rekam medis berasal dari : D-III rekam medis sebanyak 4 orang, perawat sebanyak 1 orang, fisioterapi sebanyak 1 orang, dan ekonomi sebanyak 1 orang.

b. Sistem penomoran yang digunakan adalah family folder/ penomoran keluarga namun belum dibuatkan kode/ penanda rekam medis setiap anggota keluarga.

c. Map pelindung rekam medis masih minim sehingga masih ditemukan rekam medis pasien tanpa map yang ditumpuk satu tempat sehingga pencarian dokumen rekam medis menjadi lama.

d. Ruangan penyimpanan rekam medis sangat sempit sehingga berkas rekam medis ditumpuk dalam kardus dan diletakkan di depan ruangan penyimpanan rekam medis.

e. Rak penyimpanan rekam medis masih sedikit sehingga rekam medis diletakkan di atas lantai.

f. Jenis pengarsipan yang dipakai straight numeric filling. Pengarsipan cara ini memiliki beberapa kerugian seperti kesalahan letak mudah terjadi, salah posisi (transposisi) angka sering terjadi, petugas yang mengarsipkan catatan pada saat yang sama di area tersebut akan saling menghalangi atau berbenturan, dan kontrol mutu pengarsipan susah dilakukan [6].

g. Tidak memakai outguide

h. Rekam medis pasien yang ada pada bagian penyimpanan sudah dibedakan antara aktif dengan yang tidak aktif namun masih diletakkan dalam area yang sama sehingga ruangan jadi semakin sempit.

i. Kegiatan pemusnahan berkas rekam medis belum pernah dilakukan. 


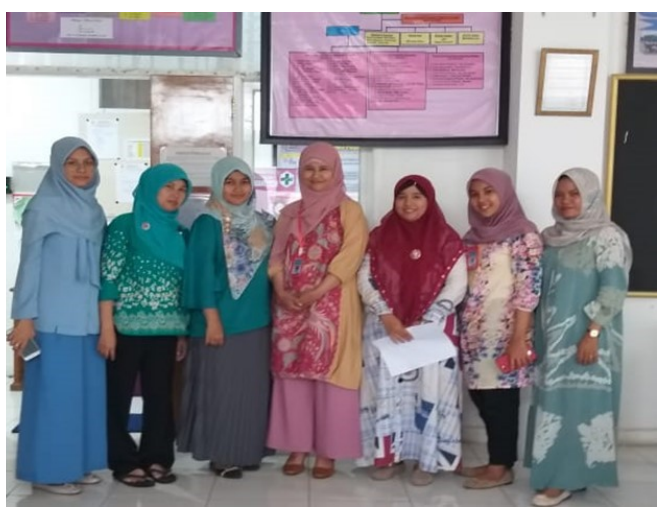

Gambar 4. Foto bersama kepala puskesmas padang pasir

\section{KESIMPULAN}

1. Adanya peningkatan pengetahuan petugas rekam medis setelah dilakukannya kegiatan sosialisasi.

2. Latar belakang pendidikan petugas rekam medis berasal dari : D-III rekam medis sebanyak 4 orang, perawat sebanyak 1 orang, fisioterapi sebanyak 1 orang, dan ekonomi sebanyak 1 orang.

3. Sistem penomoran yang digunakan family folder tanpa ada perbedaan kode nomor ayah, ibu, dan anak.

4. Sistem pengarsipan yang digunakan straight numeric filling.

5. Berkas rekam medis sudah ada dipisahkan antara aktif dengan non-aktif namun masih pada area yang sama.

6. Kegiatan pemusnahan belum pernah dilakukan hingga saat ini.

7. Pola pengarsipan sudah sentralisasi.

\section{SARAN}

a. Diharapkan petugas rekam medis berlatar belakang pendidikan minimal D-III rekam medis.

b. Ruangan rekam medis diperbesar agar berkas rekam medis bisa tersimpan dan dikelola dengan baik.

c. Diperlukan tambahan rak penyimpanan berkas rekam medis agar tidak ada lagi yang tercecer di lantai karena dapat merusak isi berkas rekam medis

d. Diperlukan adanya pemisahan antara berkas rekam medis aktif dengan tidak aktif.

e. Diperlukan kegiatan pemusnahan rekam medis untuk memperkecil volume rekam medis pasien.

f. Sistem penomoran yang digunakan Puskesmas Padang Pasir dibenarkan dengan menggunakan Family Folder namun perlu dibuatkan kode yang berbeda antara ayah, $\mathrm{ibu}$, dan anak $($ ayah $=01, \mathrm{ibu}=02$, anak $=$ 03)

g. Jenis pengarsipan yang digunakan sebaiknya menggunakan terminal digit filling.

h. Diperlukan reward/penghargaan kepada petugas rekam medis yang berguna untuk meningkatkan kinerja petugas rekam medis.

\section{UCAPAN TERIMAKASIH}

Penulis ucapan terimakasih kepada Apikes Iris yang telah memberikan bantuan Hibah PKM Apikes Iris sehingga dapat membantu terlaksananya program pengabdian kepada masyarakat ini.

\section{REFERENSI}

[1] Kemenkes RI. 2014. Permenkes RI No. 75 Tahun 2014 Tentang Puskesmas

[2] Permenpan RB RI. 2013. Permenpan RB RI No.30 Tahun 2013 tentang Jabatan Fungsional Perekam Medis dan Angka Kreditnya

[3] DKK Padang. 2017. Profil Kesehatan Kota Padang Tahun 2017

[4] Karlina, D, Putri IA, dan Dian BS. 2016. Kejadian Misfile dan Duplikasi Berkas Rekam Medis Sebagai Pemicu 
Ketidaksinambungan Data Rekam Medis. Jurnal Kesehatan Vokasional, 1(1):44-52

[5] Budi, SC. 2011. Manajemen Unit Rekam Medis. Yogyakarta : Quantum Sinergis Media

[6] Huffman, EK. 1994. Health Information
Management. Tenth Edition. Physicians Record Company. Berwyn : Illinois. Terjemahan Erkadius. 2013. Manajemen Informasi Kesehatan I. Diktat Perkuliahan. Padang:
Apikes
Iris 